Open Access

\title{
A newborn tolerated severe hypercapnia during general anesthesia: a case report
}

\author{
Kai Wei, Hui Xu, Wanmin Liao, Chuanhan Zhang and Wenlong Yao*
}

\begin{abstract}
Introduction: Severe hypercapnia is a rare but harmful complication of general anesthesia. We report the case of a newborn who developed severe hypercapnia with unknown reasons during general anesthesia but recovered well. This report will advance our understanding about the causes of severe hypercapnia during anesthesia, the possible compensatory mechanisms and the characteristics of neonatal respiratory physiology and intracellular buffering systems.

Case presentation: A 21-day-old Chinese baby girl who had an incarcerated hernia received an emergent exploratory operation under general anesthesia. She developed severe hypercapnia during surgery for unclear reasons. Arterial blood gas revealed a $\mathrm{PCO}_{2}$ of $149 \mathrm{mmHg}$. Troubleshooting and relevant measures were taken, but the level of $\mathrm{CO}_{2}$ did not decrease. In spite of the high level of $\mathrm{PCO}_{2}$, the newborn recovered well without any complications.

Conclusions: Neonates are vulnerable to hypercapnia during anesthesia for their characteristic respiratory physiology. Heat and moisture exchange should be used with caution in newborns under general anesthesia as it can increase dead space. Intracellular buffering systems play an important role in tolerating severe hypercapnia. Although this case raised a great challenge to the homeostatic mechanism of the body, measures should be taken to maintain $\mathrm{PCO}_{2}$ values around the clinically acceptable level.
\end{abstract}

\section{Introduction}

The process of lung maturation is not completed in a fullterm newborn. A European cohort of ventilated newborn babies indicated that hypercapnia was more common than hypocapnia [1]. However, severe hypercapnia can also bring some adverse effects in neonates such as periventricular white matter injury, intraventricular hemorrhage and retinopathy of prematurity [2]. Here we present and analyze the case of a newborn who experienced severe hypercapnia during general anesthesia but recovered well with no complications.

\section{Case presentation}

A 21-day-old Chinese baby girl weighing $3.8 \mathrm{~kg}$ with an incarcerated hernia underwent emergent inguinal herniorrhaphy. The newborn was a full-term delivery and was born on mixed feeding without any special medical

\footnotetext{
* Correspondence: wlyao82@126.com

Department of Anesthesiology, Tongji Hospital, Tongji Medical College, Huazhong University of Science and Technology, 1095 Jiefang Avenue, Wuhan 430030, China
}

history. Anesthesia was induced uneventfully with propofol $2.5 \mathrm{mg} \cdot \mathrm{kg}^{-1}$ and fentanyl $2 \mu \mathrm{g} \cdot \mathrm{kg}^{-1}$. She was paralyzed with atracurium $0.5 \mathrm{mg} \cdot \mathrm{kg}^{-1}$ and intubated with a size 3.0 cuffed tracheal tube. She was ventilated with a time-cycled, pressure-limited ventilation mode using a pediatric circle circuit, with a respiratory rate of $25 \mathrm{~min}^{-1}$ and maximum pressure $\left(\mathrm{P}_{\max }\right)$ of $15 \mathrm{~cm} \mathrm{H}_{2} \mathrm{O}$. The machine showed the tidal volume given to the newborn was $45 \mathrm{~mL}$. Partial pressure of end-tidal carbon dioxide ( $\left.\mathrm{P}_{\mathrm{ET}} \mathrm{CO} 2\right)$ fluctuated between 35 and $45 \mathrm{mmHg}$. Noninvasive blood pressure, electrocardiogram, pulse oximetry, $\mathrm{P}_{\mathrm{ET}} \mathrm{CO}_{2}$ and body temperature were monitored continuously and these remained within normal levels throughout induction of anesthesia. Anesthesia was maintained with sevoflurane and remifentanil.

Twenty minutes after anesthesia, $\mathrm{P}_{\mathrm{ET}} \mathrm{CO}_{2}$ increased from $45 \mathrm{mmHg}$ to $50 \mathrm{mmHg}$ and rose to $90 \mathrm{mmHg}$ in 30 minutes. The body temperature of the newborn was $37.5^{\circ} \mathrm{C}$ at the beginning of surgery. When $\mathrm{P}_{\mathrm{ET}} \mathrm{CO}_{2}$ began to rise, she flushed and her body temperature increased to $38.3^{\circ} \mathrm{C}$. The warm blanket was removed and the 
heating in the operating room was turned off. Ten minutes later, her body temperature was down to normal level.

Troubleshooting and relevant measures were taken when $\mathrm{P}_{\mathrm{ET}} \mathrm{CO}_{2}$ began to rise. The depth of the endotracheal tube was checked by auscultating both lung fields. The $\mathrm{CO}_{2}$ absorber was checked and found to be of normal condition but was still replaced. Respiratory rate and $\mathrm{P}_{\max }$ were adjusted to $40 \mathrm{~min}^{-1}$ and $18 \mathrm{~cm} \mathrm{H} \mathrm{H}_{2} \mathrm{O}$ respectively. Tidal volume showed $60 \mathrm{ml}$ at this time. Meanwhile, the $\mathrm{CO}_{2}$-analyzing line and $\mathrm{CO}_{2}$-analyzing water trap cassette were changed, but without any obvious change in $\mathrm{P}_{\mathrm{ET}} \mathrm{CO}_{2}$. Neuromuscular blockers were added to exclude the recovery of spontaneous breathing and respiratory antagonism. Manual ventilation was applied to exclude any malfunction of the anesthesia machine. In spite of all these measures, $\mathrm{P}_{\mathrm{ET}} \mathrm{CO}_{2}$ did not decrease.

Surprisingly, her heart rate and blood pressure fluctuated $\pm 20 \%$ of baseline during the increase of $\mathrm{P}_{\mathrm{ET}} \mathrm{CO}_{2}$. The operation was not interrupted and finished rapidly as there was no intestinal ischemia. Femoral artery blood gas analysis at the end of the surgery showed severe respiratory acidosis (Table 1). Twenty minutes after the blood gas analysis, there was no obvious change in $\mathrm{P}_{\mathrm{ET}} \mathrm{CO}_{2}$ but the newborn suddenly opened her eyes. She recovered spontaneous breathing. The anesthetic circuit was disconnected from the ventilator for 5 minutes and pulse oximetry saturation remained normal. So, the endotracheal tube was removed. After extubation, femoral vein blood gas analysis showed partial pressure of carbon dioxide $\left(\mathrm{PCO}_{2}\right)$ of $115 \mathrm{mmHg}$ and the neonate was sent to the pediatric intensive care unit (PICU). Two hours later, a repeat artery blood gas analysis indicated that $\mathrm{PCO}_{2}$ was $31.8 \mathrm{mmHg}$ and $\mathrm{pH}$ was 7.352. Postoperative review showed there were no complications.

\section{Discussion}

In this newborn, the main problem noted was severe hypercapnia. Infants are more likely to develop hypercapnia because of the age-related physiological changes in vital systems and a higher metabolic rate in relation to weight. The causes of hypercapnia include two aspects: the increase of $\mathrm{CO}_{2}$ generation and the decrease of $\mathrm{CO}_{2}$ discharge. Detailed factors include malignant hyperthermia, equipment and breathing circuit malfunction, patients' preexisting pulmonary diseases, $\mathrm{CO}_{2}$ pneumoperitoneum, improper ventilatory settings and invalidity of $\mathrm{CO}_{2}$ absorber. However, in the present case, we failed to determine the real cause of the hypercapnia. Malignant hyperthermia was excluded as the neonate's temperature decreased to normal level after the heating was switched off in the operating room and she did not show any sign of muscle rigidity, tachycardia, etc. $\mathrm{CO}_{2}$ canisters as well as the anesthesia machine were working properly. Time-cycled, pressure-limited ventilation mode is the most widely used mechanical ventilation mode for neonates and ventilation parameters were appropriate for the newborn.

An important factor we ignored during anesthesia was that a heat and moisture exchanger (HEM) was used between the circle system Y-piece and endotracheal tube. A circuit containing HEM can increase the dead space by almost $70 \%$ compared with a circuit without HEM in a 24-month-old child undergoing general anesthesia [3]. We did not realize the HEM was there until the tracheal extubation. It is not certain whether the HEM caused hypercapnia in this neonate, but a HEM used in pediatric anesthesia can induce hypoventilation with subsequent hypercapnia [3].

Hypercapnia is a two-edged sword and it exerts multiple physiologic effects on different organs. The word "permissive hypercapnia" was first described by Hickling in 1990 who suggested that adoption of low-tidalvolume ventilation strategies with tolerance of elevation in $\mathrm{PCO}_{2}$ was associated with lower hospital mortality [4]. Hypercapnia displaces the oxygen dissociation curve to the right, which improves tissue oxygenation and perfusion and may alleviate the injury to immature lung and brain [5]. Retrospective studies in premature neonates also concluded that higher $\mathrm{PCO}_{2}$ contributed to less lung injury [6].

In spite of these protective effects, it is believed that severe hypercapnia leads to an increase of intracranial pressure (ICP) via acidosis-induced cerebral arteriolar dilation, which is thought to be related with well-known neurological complications such as cerebral edema, intraventricular hemorrhage and temporary neurological impairment [7]. Reduced skeletal muscle contractility and decreased myocardial contractility are also known to occur following hypercapnia [8]. However, no evidence of neurological sequelae was observed in this neonate.

A few cases of severe hypercapnia have been reported in the literature. Most cases of patients with severe hypercapnia are related to chronic obstructive pulmonary disease, exacerbation of bronchial asthma causing severe hypoxemia or defective apparatus used during general anesthesia $[9,10]$. Compared with those patients, several unique characteristics in our case deserve further

Table 1 Artery blood gas at the end of the surgery

\begin{tabular}{lllllllll}
\hline $\mathrm{pH}$ & $\mathrm{pO}_{2}$ & $\mathrm{pCO}_{2}$ & $\mathrm{BE}$ & $\mathrm{Hb}$ & $\mathrm{Hct}$ & $\mathrm{K}^{+}$ & $\mathrm{Na}^{+}$ & $\mathrm{Glu}$ \\
\hline 6.831 & $94.6 \mathrm{mmHg}$ & $149 \mathrm{mmHg}$ & $-9.8 \mathrm{mmol} / \mathrm{L}$ & $11.4 \mathrm{~g} / \mathrm{dL}$ & $35 \%$ & $5.4 \mathrm{mmol} / \mathrm{L}$ & $127 \mathrm{mmol}^{2} \mathrm{~L}$ & $15.1 \mathrm{mmol} / \mathrm{L}$ \\
\hline
\end{tabular}


discussion. First, to the best of our knowledge, this is the first reported case of a neonate who developed severe hypercapnia during general anesthesia for unclear reasons. Second, the neonate regained full consciousness and no residual neurological deficit was observed.

The ability to tolerate hypercapnia varies among individuals for a broad spectrum of factors such as duration of hypercapnia, the speed at which high values are reached, maximal $\mathrm{PCO}_{2}$ value, patient age and preexisting diseases. The threshold of $\mathrm{PCO}_{2}$ above which neurological impairment occurs is unclear [11]. Hypercapnia coma has been observed in patients with $\mathrm{PCO}_{2}$ values of $58 \mathrm{mmHg}$. However, a sober patient with $\mathrm{PCO}_{2}$ values of $160 \mathrm{mmHg}$ has also been reported [12].

Remarkable renal compensation enables patients with end-stage lung disease to tolerate severe chronic hypercapnia. But how to explain why the newborn can tolerate such severe hypercapnia? The first reason could be that the neonate is insensitive to elevation of $\mathrm{CO}_{2}$. Central chemosensitivity in the newborn is not the same as that in the adult. In term neonates, the ventilatory handling of a hypercapnia challenge is fully functional on postnatal day 2 . Then during the following 8 weeks, ventilatory response to $\mathrm{CO}_{2}$ declines markedly and subsequently achieves adult level of responsiveness after the 9th week [13]. The altered $\mathrm{CO}_{2}$ sensitivity of neurons, the loss of GABAergic excitation and changes in astrocytic function during development may account for the triphasic pattern of responsiveness to the $\mathrm{CO}_{2}$ [14]. Both carotid and central chemoreceptors are important for a normal ventilatory of $\mathrm{CO}_{2}-\mathrm{H}^{+}$chemosensitivity. Nevertheless, carotid plays a greater role at low levels of hypercapnia, whereas intracranial chemoreceptors are more dominant at high levels [15]. In neonates, peripheral $\mathrm{CO}_{2}$ chemoreceptors exert greater influence than central $\mathrm{CO}_{2}$ chemoreceptors [13]. Therefore, we may infer that a nadir of ventilatory responsiveness to $\mathrm{CO}_{2}$ in this 21-day-old newborn as well as the specificity of $\mathrm{CO}_{2}$ chemoreceptors in neonates might make newborns insensitive to elevation of $\mathrm{CO}_{2}$. This might be an important reason why the neonate can tolerate severe hypercapnia.

Clinical severe hypercapnia frequently occurred with tissue hypoxia or arterial hypoxemia. However, in this newborn, this is not the case. Oxygen saturation was continuously monitored and it never fell below $95 \%$ during the increase of $\mathrm{P}_{\mathrm{ET}} \mathrm{CO}_{2}$. Hemodynamics remained stable during the anesthetic procedure, which also guaranteed tissue perfusion and oxygenation. Research has indicated that the central system has a potent ability to recover from nonhypoxic severe respiratory acidosis [9]. As long as tissue perfusion and oxygenation are preserved, effective transfer of $\mathrm{HCO}_{3}^{-}$from extracellular space into cells by $\mathrm{Na}^{+} / \mathrm{K}^{+}$changes or $\mathrm{Na}^{+} / \mathrm{H}^{+}$changes will continuously occur when exposing to hypercapnia
[10]. Consequently, the drop of $\mathrm{pH}$ in intracellular cells is far slower than that in extracellular cells. It is important to note that this regulation is energy-consumed, which requires the cells to be oxygenation and perfused [10]. The adequate oxygenation and strong chemical buffering capacity in intracellular cells enable important organs to tolerate extreme acidosis and that might contribute to the benign outcome of the newborn.

\section{Conclusions}

Gross hypercapnia occurs rarely during general anesthesia. Heat and moisture exchange should be used with caution in newborns under general anesthesia as it can increase dead space. This study will significantly advance our understanding about the characteristics of neonatal respiratory physiology, intracellular buffering systems, and causes of severe hypercapnia. Although this case raised a great challenge to the homeostatic mechanism of the body, measures should be taken to maintain $\mathrm{PCO}_{2}$ values around the clinically acceptable level.

\section{Consent}

Written informed consent was obtained from the patient's legal guardians for publication of this case report and any accompanying images. A copy of the written consent is available for review by the Editor-in-Chief of this journal.

\section{Competing interests}

The authors declare that they have no competing interests.

\section{Authors' contributions}

KW and WL collated the data. HX, WL and WY contributed to the patient management. KW and WY wrote the manuscript. CZ and HX provided critical revision of the manuscript. KW and WY were responsible for the final manuscript. All authors read and approved the final version to be submitted.

\section{Acknowledgements}

This work was supported by grants from National Natural Science Foundation of China (81171158).

Received: 30 May 2015 Accepted: 20 August 2015 Published online: 14 September 2015

\section{References}

1. van Kaam AH, De Jaegere AP, Rimensberger PC, Neovent Study Group Incidence of hypo- and hyper-capnia in a cross-sectional European cohort of ventilated newborn infants. Arch Dis Child Fetal Neonatal Ed. 2013;98:F323-6.

2. Pray-Roberts C, Smith WDA, Nunn JF. Accident severe hypercapnia during anesthesia-A case report and review of some physiological effect. Brit J Anaesth. 1967;39:257-65.

3. Karlin A, Umeh U, Girshin M. Hypercapnia and tachycardia in a 2-year old. Paediatr Anaesth. 2009;19:629-30.

4. Hickling KG, Henderson SJ, Jackson R. Low mortality associated with low volume pressure limited ventilation with permissive hypercapnia in severe adult respiratory distress syndrome. Intensive Care Med. 1990;16:372-7.

5. Jankov RP, Tanswell AK. Hypercapnia and the neonate. Acta Pædiatr. 2008;98:1502-9.

6. Gannon CM, Wiswell TE, Spitzer AR. Volutrauma, $\mathrm{PaCO}_{2}$ levels, and neurodevelopmental sequelae following assisted ventilation. Clin Perinatol. 1998;25:159-75. 
7. Zayek M, Alrifai W, Whitehurst R, Kua K, Martino A, Eyal F. Acidemia versus hypercapnia and risk for severe intraventricular hemorrhage. Am J Perinatol. 2014;31:345-52.

8. Varughese M, Patole S, Shama A, Whitehall J. Permissive hypercapnia in neonates: the case of the good, the bad, and the ugly. Pediatr Pulmonol. 2002;33:56-64

9. Urwin L, Murphy R, Robertson C, Pollok A. A case of extreme hypercapnia: implications for the prehospital and accident and emergency department management of acutely dyspnoeic patients. Emerg Med J. 2004;21:119-20.

10. Potkin RT, Swenson ER. Resuscitation from severe acute hypercapnia. Determinants of tolerance and survival. Chest. 1992;102:1742-5.

11. Sayers JA, Smith RE, Holland RL, Keatinge WR. Effects of carbon dioxide on mental performance. J Appl Physiol (1985). 1987;63:25-30

12. Meissner HH, Franklin C. Extreme hypercapnia in a fully alert patient. Chest. 1992;102:1298-9.

13. Søvik S, Lossius K. Development of ventilatory response to transient hypercapnia and hypercapnic hypoxia in term infants. Pediatr Res. 2004;55:302-9

14. Putnam RW, Conrad SC, Gdovin MJ, Erlichman JS, Leiter JC. Neonatal maturation of the hypercapnic ventilatory response and central neural $\mathrm{CO}_{2}$ chemosensitivity. Resp Physiol Neurobiol. 2005;149:165-79.

15. Forster HV, Martino P, Hodges M, Krause K, Bonis J, Davis S, et al. The carotid chemoreceptors are a major determinant of ventilatory $\mathrm{CO}_{2}$ sensitivity and of $\mathrm{PaCO}_{2}$ during eupneic breathing. Adv Exp Med Biol. 2008;605:322-6.

\section{Submit your next manuscript to BioMed Central and take full advantage of:}

- Convenient online submission

- Thorough peer review

- No space constraints or color figure charges

- Immediate publication on acceptance

- Inclusion in PubMed, CAS, Scopus and Google Scholar

- Research which is freely available for redistribution 